\title{
SURVIVAL AND DISINFECTION OF SARS-COV-2 IN \\ ENVIRONMENT AND CONTAMINATED SURFACE
}

\author{
Adel Al-Gheethi ${ }^{1}$, *, Efaq Noman ${ }^{2,3}$, Qais Al-Maqtari ${ }^{4}$, Reyad \\ Almoheer $^{5}$, Radin Mohamed ${ }^{l}$, Rafidah Hamdan ${ }^{l}$ \\ ${ }^{I}$ Micropollutant Research Centre (MPRC), Faculty of Civil \\ Engineering \& Built Environment, Universiti Tun Hussein \\ Onn Malaysia,86400 Parit Raja, Batu Pahat, Johor, \\ Malaysia \\ ${ }^{2}$ Department of Applied Microbiology, Faculty of Applied \\ Science, Taiz University, Yemen \\ ${ }^{3}$ Faculty of Applied Sciences and Technology, Universiti Tun \\ Hussein Onn Malaysia (UTHM), KM11 Jalan Panchor, \\ 84000, Pagoh, Muar, Johor, Malaysia \\ ${ }^{4}$ Department of Biology, Faculty of Sciences, Sanaa \\ University, Yemen \\ ${ }^{5}$ Faculty of science and marine environment, University \\ Malaysia Terengganu, 21030 Kuala Nerus. Terengganu, \\ Malaysia
}

\begin{abstract}
The detection of SARS-Cov-2 in the sewage and water resources has increased the awareness among the people about the possibility survival of SARS-Cov-2 in the environment and the potential to transmit into the human through food chain or water resources. Moreover, the surface contaminated by the virus need to be disinfected frequently by using an effective disinfectant, the current chapter discussed the efficiency of the most traditional
\end{abstract}


treatment process of the sewage and wastewater, and their role in the elimination of the virus as well as the sterility assurance level concept. Moreover, the chemical disinfectant used currently and their temporary efficiency has been reviewed.

Keyword; disinfection; covid-19; sterility assurance level

\subsection{INTRODUCTION}

SARS-Cov-2 is an enveloped, single-stranded RNA and positivesense virus, classified virus classified within Coronaviruses (CoVs) genus. The bats, rodents, avian species represent the natural reservoir. SARS-CoV -2 cause a human disease similar to severe acute respiratory syndrome $\mathrm{CoV}$ (SARS-CoV) which was transmitted from bats and the Himalayan palm civet (Paguma larvata) in 2002-2003, China, as well as Middle East respiratory syndrome $\mathrm{CoV}$ (MERS-CoV) transmitted from dromedary camel (Camelus dromedaries) in the Arabian Peninsula since 2012. SARSCOV -2 cause a self-limiting upper and lower respiratory infections in people with immune-competent. It has been detected that SARSCOV -2 has $89 \%$ of similarity in the nucleotide to bat SARS-likeCoVZXC21, while has $82 \%$ of similarity with that of human SARS$\mathrm{CoV}[1-3]$.

One of the main serious problems with SARS-COV -2 is the transmission route. It has been revealed that the virus has easily 
transmission route through the respiratory droplets as well as survive for more than one day in the environment. It is hypothesized that there is a risk exposure of the virus to environmental surface, which has not yet identified. In a comparison to SARS- and MERS$\mathrm{CoV}$ pandemic which has associated with super spreading ( $\mathrm{R}$ is 3.5). Therefore, the indoor and outdoor surface should be disinfected frequently $[4,5]$. This chapter aimed to review the environmental aspects for SARS-CoV -2. The presence of SARS-CoV -2 in the hospital wastewater and the suggested treatment of these wastes are discussed. Moreover, the disinfection of the virus contaminated surface was also discussed in this chapter.

\section{SARS-COV-2 IN THE ENVIRONMENT}

Hospital wastewater contains heavily load of pathogenic bacteria and viruses. However, SARS-COV-2 which is transmitting through fecal-oral route is the most concern associated with the disposal of hospital wastewater into the environment. It has been indicated by the researchers in the literature review that the pathogenicity and virulence factors of the infectious agents lie in the ability to survive in the environment as well as the high potential to transmit into the human and animals without a host cell [6]. Based on abovementioned, the hospital effluents should be subjected for an efficient disinfection process before the final disposal into the environment. However, there are two factors should be considered for any disinfection process, these factors are biological indicators 
and the assessment procedure for the disinfection process. The selection of indicator for evaluating the efficiency of disinfection process is depending on the nature of inactivation process such as chemical or physical process. The response of indicator organisms reflects the behaviour of infectious agents. Therefore, bacteriophages are used as indicator for human viral pathogens [7].

Although, the absence scientific reports for the presence of SARS-COV-2 in sewage a number of studies have shown high levels of viral shedding in faecal samples from SARS-COV -2 patients [8,9]. Besides, some of the news reports in France and Netherland indicated to presence of Gene fragments of SARS-COV -2 in the sewage and water surface.

\section{TREATMENT OF HOSPITAL WASTEWATER}

Many of the treatment process used for wastewater treatment focus mainly on inactivating pathogenic bacteria that are harmful to aquatic life. However, recent studies revealed that detectable amounts of pathogens remain in effluents, even after sewage treatment [10]. The most common disinfectants is the chlorine, but chlorination has a side effect on the environment and might be harmful to aquatic organisms in streams that receive the effluent. Chlorine also may lead to the production of nitrosodimethylamine (NDMA) that is known to be carcinogenic to humans. The chlorination process can react with organic matter, forming another carcinogenic compound called trihalometanes (THMs) [11]. 
Moreover, conventional filtration in wastewater is not efficient for the removal of micropollutant such as viruses. However, microbial is found to be resistance to chemical materials among different types of microorganisms. In addition to occurrence of bacterial regrowth after the treatment by these techniques has been reported by AlGheethi et al. [12].

The use of solar disinfection (SODIS) based technologies is a promising approach to the disinfection of water and wastewater because of the high availability of solar radiation as well as the low cost and sustainable nature of these water treatment methods [13]. In contrast, the application of nanotechnology in the wastewater treatment has been reported in the literature [14]. Noman et al. [15] investigated the inactivation of antibiotic-resistant Escherichia coli (Gram-negative) and Staphylococcus aureus (Gram-positive) seeded in greywater by bimetallic bio-nanoparticles. The bimetallic nanoparticles ( $\mathrm{Zn} / \mathrm{Cu}$ NPs) were biosynthesized in secondary metabolite of a novel fungal strain identified as Aspergillus iizukae EAN605. The study revealed high efficiency for $\mathrm{Zn} / \mathrm{Cu}$ NPs in inhibiting the growth of E. coli and $S$. aureus. The inactivation mechanism revealed that the bacterial cells were inactivated due to the damage in the cell wall structure as well as the degradation of carbohydrates and amino structures on the bacteria cell wall. The Fourier Transform Infrared Spectroscopy (FTIR) analysis confirmed that the destruction takes place in the $\mathrm{C}-\mathrm{C}$ bond of the functional groups available in the bacterial cell wall.

Based on the aforementioned, the combination between 
SODIS and nanotechnology might provide a novel disinfection processes for the inactivation of human viruses. Among several nanoparticles, $\mathrm{ZnO}$ nanoparticles are the most common used for wastewater disinfection and these particles are might be more efficient under the sunlight which might increase the antiviral activity [16,17].

Sterility assurance level (SAL) (term use to describe the killing efficiency of a treatment process, where treatment process is very effective if SAL was very low as described by ISO 13408-1 [18] and log reduction (accepted by USEPA) terms are the most common used for assessing the efficiency of disinfection processes. SAL is normally expressed as $10^{-\mathrm{n}}$ with historically, a $10^{-3}$ or a $10^{-}$ ${ }^{6}$ value being used most frequently for sterilization dependent on the initial concentrations of the pathogens. Log reduction is calculated as $\left(10^{-1}\right)$ represents for $90 \%$ of the reduction in the microbial population. The disinfection process with "6-log reduction" $\left(10^{-6}\right)$ indicate that the microbial population reduced from a million $\left(10^{6}\right)$ to very close to zero or $99.9999 \%$. A kill rate of $99.99 \%$, is expressed in terms as a $4 \mathrm{log}$ reduction.

Moreover, in order to confirm the safe disposal of the treated effluents, the inactivated bacterial regrowth should be conducted as indicator for viral inactivation. To verify this fact, the isolation on enrichment medium is the suitable methods, where the microbial cell is considered dead if they fail to form colonies on the culture medium. However, the storage conditions of the disinfected sample might affect the ability of bacteria to regrow. Al-Gheethi et 
al. [18] revealed that Salmonella spp. S. aureus and E. faecalis regrow again in the sewage samples treated with solar disinfection (SODIS) for $6 \mathrm{hrs}$ and stored at $37^{\circ} \mathrm{C}$ for 4 days. The bacterial regrowth is occurring due to the insufficiency of the disinfection process to physically damage of bacterial cell and in this case the pathogen growth potential (PGP) bioassay needs to be carried out.

\section{DISINFECTION OF VIRUSES CONTAMINATED SURFACE}

The efficiency of several disinfectants against the microbes is depend on the ability to make irreversible destruction for the microbe cells. Several methods are used for the disinfection process, included physical and chemical process. However, the concept of chemical disinfection is depending on inhibition of a critical metabolic and anabolic pathway which in role will lead to stop the microbe activity reversible or irreversible. In some microbe, the cell has an alternative metabolic pathway and in this case the microbe can be active again. In contrast, the physical disinfection depends on the destruction for the microbe cell cytoplasm physically. These destructions are irreversible, at which the microbe cells have no potential to back again for the normal activity due to the damage for the all cell enzymes.

In comparison, the virus has no metabolic activity. Although the mechanisms of virus inactivation by chemical disinfections still not understood well, it was reported that the 
lipophilic disinfectants and chaotropic agents have little difficulty in breathing a normal lipid bilayer [19]. Moreover, the veridical efficiency of chemical disinfection might act by denaturing the virus envelops which is derived from portions of the host cell membranes (phospholipids and proteins) and protect the virus genome. Nonetheless, the denaturation of virus envelop might not lead to damage of the virus genome. Based on this principle, many of the chemical disinfectants such as alcohol (70\%), chlorine, soap and detergent might have not enough efficiency for inactivation of virus genome. The physical disinfection such as temperature and pressure would have more efficient, since it's going to destruct both virus envelope and genome.

One more limitation for the chemical disinfectants is the stability in the environment. The inactivation of virus on the surface by the alcohol or detergents might take place immediately. However, the outdoor public surface might expose for the virus contamination again, since the limitation of chemical disinfectants being distributed. The alcohol and other disinfectants loss their activity against the viruses or any microbe after few mins, might be due to the high evaporation rate especially in the tropical countries. It has been demonstrated that the natures of disinfectant chemical play an important role in determining disinfectant efficacy, since the process is influenced by environmental parameters such as temperature and relative humidity.

In the chlorination of water and wastewater, there is amount of residual chlorine constitutes an important safeguard 
against the risk of subsequent microbial contamination after treatment [20]. The diluted chlorine also has an efficient for inactivation of virus. However, the diluted chlorine should be prepared daily, because the solution reacts with the light and lost the activity [21]. Hence, the residual chlorine is not available for surface disinfection. Therefore, the outdoor surfaces such as in the transportation, and public place should be disinfected frequently. For this reason, there is an urgent to find a disinfectant has more activity stability under the environmental conditions to be active against frequently surface contamination.

SARS-COV -2 has the ability to survival for long periods (might reach to $24 \mathrm{hrs}$ ), while the chemical disinfectants spread on the contaminated surface has short stability in their activity. In this matter, the nanoparticles which also have antiviral activity against H1N1 has a longer stability under different environmental conditions [17]. The biosynthesis of NPs represents the alternative for chemical and physical synthesis process. For instance, fungi contain proteins, enzymes and reducing components on its cell surface and produce reducing agents such as napthoquinones and anthraquinones [22]. Therefore utilizing fungi as the stabilizing/reducing agent is very effective in producing NPs with well-defined morphologies as they produce different types of intracellular enzymes for the development of metal and metal oxide NPs. Since fungi have high binding capacity, tolerance and metal bio-accumulation ability and the intracellular intake they are utilized to synthesize metallic NPs. Synthesis of NPs by fungi is more 
beneficial compared to other microorganisms as fungi are easy to isolate and culture grow faster than bacteria and easy to handle and produce in the laboratory [15].

Thematically the $\mathrm{ZnO}-\mathrm{NPs}$ with size less than $100 \mathrm{~nm}$ have high potential to penetrate the SARS-COV -2 virus with size of $400 \mathrm{~nm}$ and breakdown the virus genome physically. Besides, $\mathrm{ZnO}-$ NPs play dual role such as anti-adhesive and antimicrobial agent simultaneously and has the ability to be stable on the surface under different environmental conditions such has humidity and temperature [23]. However, SARS-COV -2 has a high risk and therefore, the current project aim to investigate the effectiveness of bio $\mathrm{ZnO}-\mathrm{NPs}$ as a nano-disinfectant against a bacteriophage virus as a model.

\section{CONCLUSION}

It can be concluded that the presence of SARS-Cov-2 in the water and wastewater represent an indication for the distribution of the virus in the surrounding community. There is no evidence for the pathogenicity of the detected DNA fragments in the wastewater. Moreover, the survival of the virus on the surface needs an effective disinfectant to confirm the inactivation of the virus activity.

\section{ACKNOWLEDGEMENT}


The authors wish to express thanks to the Ministry of Education Malaysia through FRGS vot K090 and Research Management Centre (RMC) Universiti Tun Hussein Onn Malaysia (UTHM Contract Grant H377 and M003) for funding this work.

\section{REFERENCES}

[1] Woo PC, Lau SK, Chu CM, Chan KH, Tsoi HW, Huang Y, Wong BH, Poon RW, Cai JJ, Luk WK, Poon LL. Characterization and complete genome sequence of a novel coronavirus, coronavirus HKU1, from patients with pneumonia. Journal of virology. 2005 Jan 15;79(2):884-95.

[2] Chan JF, Kok KH, Zhu Z, Chu H, To KK, Yuan S, Yuen KY. Genomic characterization of the 2019 novel humanpathogenic coronavirus isolated from a patient with atypical pneumonia after visiting Wuhan. Emerging Microbes \& Infections. 2020 Jan 1;9(1):221-36.

[3] Liu, Y., Rosenfield, E., Hu, M. and Mi, B., 2013. Direct observation of bacterial deposition on and detachment from nanocomposite membranes embedded with silver nanoparticles. Water research, 47(9), pp.2949-2958.

[4] Gralinski LE, Menachery VD. Return of the Coronavirus: 2019nCoV. Viruses. 2020 Feb;12(2):135.

[5] Wang M, Cao R, Zhang L, Yang X, Liu J, Xu M, Shi Z, Hu Z, Zhong W, Xiao G. Remdesivir and chloroquine effectively 
inhibit the recently emerged novel coronavirus (2019-nCoV) in vitro. Cell Research. 2020 Feb 4:1-3.

[6] Ceustermans, A., De Clercq, D., Aertsen, A., Michiels, C., Geeraerd, A., Van Impe, J., Coosemans, J. \& Ryckeboer, J. (2007). Inactivation of SalmonellaSenftenberg strain W 775 during composting of biowastes and garden wastes. Journal of Applied Microbiology, 103(1), 53-64.

[7] Dias, E., Ebdon, J. and Taylor, H., 2018. The application of bacteriophages as novel indicators of viral pathogens in wastewater treatment systems. Water research, 129, pp.172179.

[8] Hindson, J., 2020. COVID-19: faecal-oral transmission?. Nature Reviews Gastroenterology \& Hepatology, pp.1-1.

[9] Chen, Y., Chen, L., Deng, Q., Zhang, G., Wu, K., Ni, L., Yang, Y., Liu, B., Wang, W., Wei, C. and Yang, J., 2020. The Presence of SARS-CoV-2 RNA in Feces of COVID-19 Patients. Journal of Medical Virology.

[10] Spongberg AL, Witter JD (2008) Pharmaceutical compounds in the wastewater process stream in Northwest Ohio. Journal Science Environment, 397: 148-157.

[11] Kumari, M., Gupta, S.K. and Mishra, B.K. 2015. Multiexposure cancer and non-cancer risk assessment of trihalomethanes in drinking water supplies - A case study of Eastern region of India. Ecotoxicology and Environmental Safety, Vol 113, 433-438.

[12] AL-Gheethi, A.A., Ismail, N., Lalung, J., Talib, A. and Kadir, 
M.O.A., 2013. Reduction of Faecal Indicators and Elimination of Pathogens from Sewage Treated Effluents by Heat Treatment. Caspian Journal of Applied Sciences Research, 2(2).

[13] Gomez-Couso, H.; Fontan-Sainz, M.; Sichel, C.; FernandezIbanez, P. and Ares-Mazas, E. (2009) Efficacy of the solar water disinfection method in turbid waters experimentally contaminated with Cryptosporidium parvum oocysts under real field conditions. Trop. Med. Int. Health. 14 (6): 620627.

[14] Athirah A, Al-Gheethi AAS, Noman EA, Mohamed RMSR, Kassim AHM (2019) Centralised and decentralised transport systems for greywater and the application of nanotechnology for treatment processes. In: Management of greywater in developing countries. Springer, Cham, pp 227244

[15] Noman, E., Al-Gheethi, A., Talip, B.A., Mohamed, R. and Kassim, A.H., 2019. Inactivating pathogenic bacteria in greywater by biosynthesized $\mathrm{Cu} / \mathrm{Zn}$ nanoparticles from secondary metabolite of Aspergillus iizukae; optimization, mechanism and techno economic analysis. PLoS One, 14(9).

[16] Siddiqi, K.S., Husen A (2016a) Fabrication of metal nanoparticles from fungi and metal salts: scope and application. Nano Res Lett, 11, p.98.

[17] Ghaffari, H., Tavakoli, A., Moradi, A., Tabarraei, A., Bokharaei-Salim, F., Zahmatkeshan, M., Farahmand, M., 
Javanmard, D., Kiani, S.J., Esghaei, M. and PirhajatiMahabadi, V., 2019. Inhibition of H1N1 influenza virus infection by zinc oxide nanoparticles: another emerging application of nanomedicine. Journal of biomedical science, 26(1), p.70.

[18] Al-Gheethi, A. A., Norli, I., \& Kadir, M. O. A. (2013). Elimination of enteric indicators and pathogenic bacteria in secondary effluents and lake water by solar disinfection (SODIS). Journal of Water Reuse and Desalination, 3(1), 39-46.

[18] ISO, (1998). International Standard Organisation, Aseptic Processing of Health Care Products, Part 1, general Requirements, International Standard ISO 13408-1 (1998).

[19] Springthorpe, V.S. and Sattar, S.A., 1990. Chemical disinfection of virus-contaminated surfaces. Critical Reviews in Environmental Science and Technology, 20(3), pp.169-229.

[20] Al-Gheethi, A.A., Efaq, A.N., Bala, J.D., Norli, I., AbdelMonem, M.O. and Kadir, M.A., 2018. Removal of pathogenic bacteria from sewage-treated effluent and biosolids for agricultural purposes. Applied Water Science, 8(2), p.74.

[21] Trajano, D., Dias, E., Ebdon, J. and Taylor, H., 2016. Limitations of chlorine disinfection of human excreta: Implications for Ebola disease control.

[22] Siddiqi, K.S., ur Rahman, A. and Husen, A., 2018. Properties 
of zinc oxide nanoparticles and their activity against microbes. Nanoscale research letters, 13(1), pp.1-13.

[23] Liu, Z., Magal, P., Seydi, O. and Webb, G., 2020. Understanding Unreported Cases in the 2019-Ncov Epidemic Outbreak in Wuhan, China, and the Importance of Major Public Health Interventions. China, and the Importance of Major Public Health Interventions (February 3, 2020). 